\title{
The Efficiency of a Patient \& Doctor Role-play as a Participatory Clinical Clerkship in Korean Dermatology Department
}

\author{
You-jin Chang, Seung-ug Hong \\ Dept. of Korean Medical Ophthalmology \& Otolaryngology \& Dermatology, \\ College of Korean Medicine, Dongguk University
}

\begin{abstract}
Objectives: The purpose of this study was to evaluate the efficiency of patient and doctor role-play on participatory clinical clerkship by surveying student's satisfaction and assessing the improvement of skill and consultation ability after conducting a role-play in a Korean dermatology department.

Methods: In 2013, 79 seniors participated in the clinical clerkship of the dermatology department at the college of Korean medicine. Two students were randomly selected and paired up. After a brief instruction, one student played the role of doctor and the other took the role of patient. After finishing the $1^{\text {st }}$ role-play, they swapped roles and conducted a $2^{\text {nd }}$ role-play, using another clinical case. When the two role-plays were completed, the students filled in a questionnaire about their satisfaction with the role-play as clinical clerkship. Also, we compared the scores of the $1^{\text {st }}$ role-play with those of the $2^{\text {nd }}$ role-play measured by a medical resident to assess improvements of students' skill and interview ability.

Results: It appears that students' satisfaction with the role-play was quite high, considering that the overall mean score of the questionnaire was 4.30. According to the result of a t-test on 15 assessment questions, the $2^{\text {nd }}$ role-play had a higher mean score than the $1^{\text {st }}$ role-play in 12 questions, though this difference was not statistically significant. Conclusions: These results demonstrate that role-play is helpful to improve students' satisfaction and clinical performance ability in clinical clerkship. Further research and continuous development are necessary for better clinical clerkship.
\end{abstract}

$\overline{\text { Key Words }}$ : Role-play, participatory clinical clerkship, efficiency

\section{Introduction}

The purpose of medical education is to acquire comprehensive competence including knowledge, skill, problem solving ability, attitude, etc ${ }^{1)}$. Recently, medical education has put more emphasis on the importance of acquisition of skills and attitudes needed for the betterment of clinical performance, different from the past which emphasized simply on knowledge acquisition. As it is widely perceived that doctors freshly graduated from medical school lack in clinical performance ability, reformation of medical education has been rising in our society ${ }^{2-4)}$. These days the importance of implementing interview training for medical students has been underscored because it is reported that effective interpersonal communication between patient and doctor can increase satisfaction, leading

\footnotetext{
- Received : 19 November 2013

- Revised : 3 December 2013

- Accepted : 3 December 2013

- Correspondence to: Seung-ug Hong

Dept. of Korean Medical Ophthalmology \& Otolaryngology \& Dermatology, Dongguk University IIsan Hospital, Siksa-Dong 814, Ilsandong-Gu, Goyang-Si, Kyunggi-Do, Republic of Korea.

Tel : +82-31-961-9085, Fax : +82-31-961-9085, Email : heenthsu@duih.org
} 
to an increase of patient compliance and treatment effect by forming good patient-physician interaction $(\mathrm{PPI})^{5-8)}$. As the fact that it is possible for patient-physician interaction to improve by training becomes known ${ }^{9,10)}$, many medical colleges seek methods to instruct and appraise skills and attitude as well as knowledge.

Since the 1980's, Problem Based Learning (PBL), Standardized Patients (SP), Simulation, Role-play, etc., have been tried as teaching methods and objective structured clinical examination (OSCE), clinical performance examination (CPX), etc. have been developed as clinical skills assessment tools. In Korea, they have been widely utilized in colleges and medical board examination since several years ago. Recently, role-play has been used actively for the following reasons. First, it is a safe method because it is not likely to damage real patients. Moreover it is possible that students can repeatedly observe and practice in the environment similar to the real one and this motivates students to study hard. For these reasons, role-play is widely practiced as a training and assessment method in many medical colleges ${ }^{11,12)}$.

In colleges of Korean medicine, OSCE and CPX have been used as an assessment tool for clinical clerkship since 2011 and many attempts have been made such as studies of Pulse Simulator ${ }^{13)}$, Standardized Patient ${ }^{14)}$, role-play program ${ }^{15)}$ and so on. However, there was no study on the effectiveness of role-play in dermatology diseases. Thus, the department of Ophthalmology \& Otolaryngology \& Dermatology at the Korean medical school of Dongguk University conducted patient and doctor role-play as one tool of participatory clinical training in order to improve students' ability of clinical performance and consultation skills, and assess the effectiveness of the role-play on clinical performance education through student satisfaction survey and evaluation of skills and consultation ability.

\section{Subjects and Method}

In 2013, in the clinical clerkship coursework of dermatology department, 79 seniors in the college of Korean medicine participated in the role-play as groups of 6 or 7 people. To begin with, a medical resident explained the objective of the role-play and lectured students on the basic knowledge required for consultation with patients. A few days later, two students were randomly chosen in each group. One student carried out the role of doctor, and the other took the role of patient after he/she had thoroughly read an instruction which described the patient skin condition and history. Highly prevalent skin diseases such as atopic dermatitis, psoriasis and acne were selected as cases and the symptoms of each case were given to students to act as the patient. Clinical pictures of skin lesions and the results of pulse and tongue diagnosis were provided to students who acted as the doctor only when they really conducted an action to a patient (Table 1).

The $1^{\text {st }}$ role-play proceeded for about 15 minutes and a medical resident observed and assessed the student who conducted the role of doctor (Table 2). In the $2^{\text {nd }}$ role-play, the two students swapped roles and another case was used. After the two role-plays were finished, the medical resident gave a brief account of the cases and provided them with feedback. Afterward, the students filled in a questionnaire (Table 3).

The evaluation form and questionnaire were developed on the basis of previous domestic research related to clinical practice training and evaluation of Western medicine ${ }^{12,13)}$ and were made up of multiple-choice questions.

The questionnaire and the evaluation form used five scale ratings by Likert, such as Strongly disagree (1), Disagree (2), Neither agree nor disagree (3), Agree (4), Strongly agree (5). Collected data was processed using SPSS 12.0 for Windows and reliability of each question was evaluated by the 
Table 1. Descriptions of Cases

\begin{tabular}{|c|c|}
\hline \multicolumn{2}{|l|}{ Description } \\
\hline $\begin{array}{l}\text { Case } 1 . \\
\text { Atopic dermatitis } \\
\text { (Heat and } \\
\text { dryness Type) }\end{array}$ & $\begin{array}{l}\mathrm{F} / 11,150 \mathrm{~cm} / 40 \mathrm{Kg} \\
\text { Symptoms have begun } 3 \text { to } 4 \text { years ago. In the beginning, my skin was } \\
\text { swollen and covered with weeping sores, and these days it is so dry } \\
\text { that I continuously scratch itchy spots and feel burning. Symptoms } \\
\text { mostly appeared around the eye and lip areas, post neck and the } \\
\text { anterior flexural crease of the elbow. Skin conditions become } \\
\text { aggravated when seasons change and when I have ready-to-eat food. } \\
\text { I took steroid medicine and applied topical ointments, but they didn't } \\
\text { help. Good appetite and digestion, Constipation tends, Red tongue, } \\
\text { Thin tongue coating, Slippery and rapid pulse. History of allergic } \\
\text { rhinitis. }\end{array}$ \\
\hline $\begin{array}{l}\text { Case } 2 . \\
\text { Psoriasis } \\
\text { (Wind-heat and } \\
\text { blood-heat Type) }\end{array}$ & $\begin{array}{l}\mathrm{M} / 44,170 \mathrm{~cm} / 80 \mathrm{Kg} \\
\text { The skin of the elbow has started turning red and becoming itchy } \\
\text { since last March. Although I consulted with a DM doctor and took } \\
\text { medicine for } 2 \text { months, it has not been getting better. I visited here } \\
\text { because it has suddenly become worse from this December. Skin } \\
\text { color turns crimson and round-shape plaques are developed on the } \\
\text { skin of scalp, back, elbows and knees. Dead skin cells were formed on } \\
\text { these spots, which give them a silvery-white appearance. When these } \\
\text { scales are scraped off, punctate bleeding spots appear. Itching } \\
\text { becomes more intense during the night than the daytime. Drinking } \\
\text { alcohol and having oily foods frequently, Amicable personality, } \\
\text { Urine color deepness, Red tongue, Yellowish tongue coating, Rapid } \\
\text { pulse. }\end{array}$ \\
\hline
\end{tabular}

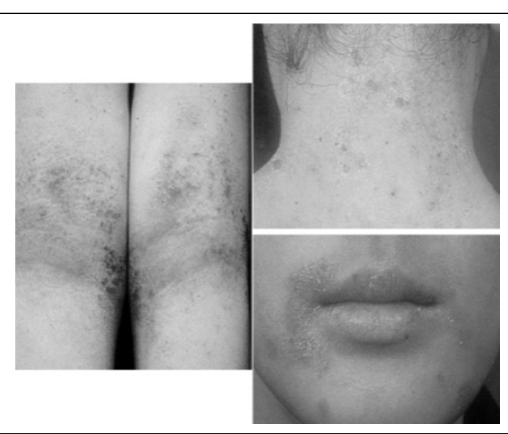

\section{$\mathrm{F} / 29,165 \mathrm{~cm} / 55 \mathrm{Kg}$}

Though I had fine skin before, I started to have whiteheads on my forehead and chin since I have been stressed for recent five to six Case 3. months. When I squeezed the pimples with my fingers, sebum

Acne

(Stagnation of Liver Qi Type) secreted and skin turned red. Several severe spots formed pus and got darkened as pigment built up. Meanwhile, I didn't receive any particular treatment and merely washed my face with clean water several times a day. Nowadays it seemed that menstrual cycle has been lengthened and I frequently have a digestive problem. Red tongue, Thin and whitish tongue coating, Rapid pulse.

\section{$\mathrm{F} / 31,163 \mathrm{~cm} / 57 \mathrm{Kg}$}

I had symptoms and got therapy in my youth, and afterward I keep improving. Lately, symptoms have taken a sudden turn for the worse after I have been to the US for business for six months. Skin presents red eruptions and became swollen around them and rubbing or

Case 4 .

Atopic dermatitis (Heat and damp Type) scratching in this area causes oozing and crusting. The symptoms were particularly severe on elbow, popliteus, hands and feet. Pruritus are more intense in hot and humid conditions. I applied topical ointment that was prescribed by a dermatologist for two weeks, but it didn't have a good effect. Despite of good appetite, I frequently have bloating and gas. I'm gaining a lot of weight recently. Normal defecation, Red tongue, Slightly yellowish tongue coating, Slippery and rapid pulse.
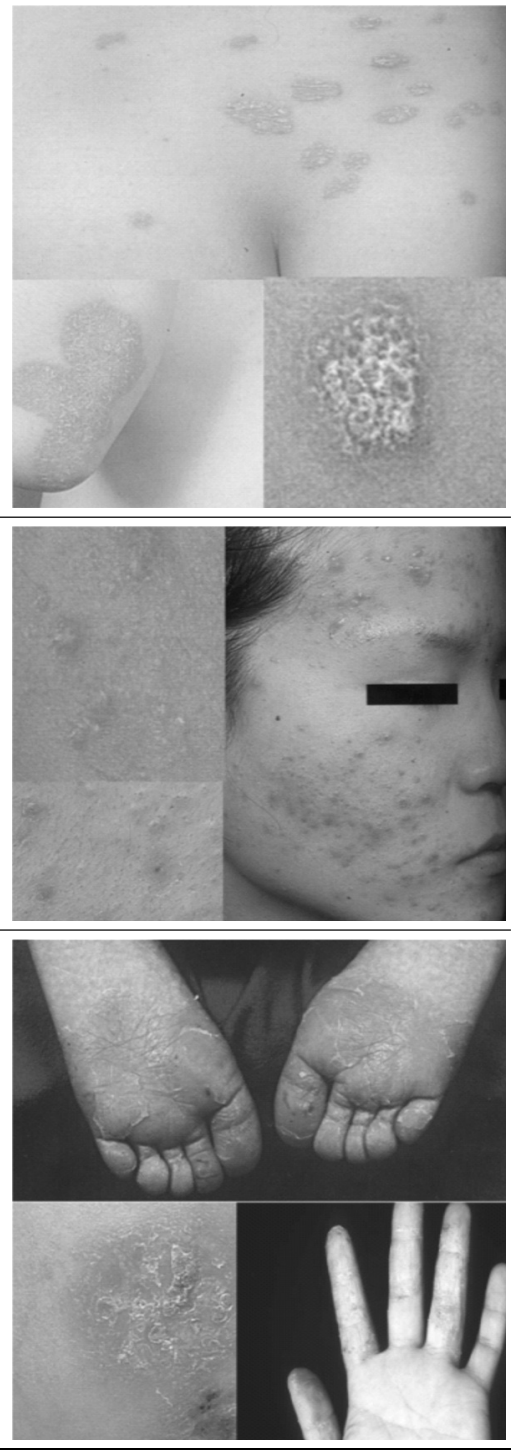
Description

\section{$\mathrm{M} / 25,178 \mathrm{~cm} / 65 \mathrm{Kg}$}

Symptoms appeared four to five years ago. At the beginning, skin

Case 5. Psoriasis (Wind dryness due to syndrome of blood deficiency Type) lesions became reddened, thickened, and had silvery white scaling. Although I have maintained improved conditions after taking pills and rubbing salve, it was not completely healed. These days skin is so dry that lesions are itchy more often, skin has become thickened and I felt pain due to the occurrence of cracks. The symptoms appeared on my elbow, knee and scalp. Recently, I feel tired very often and dizziness from time to time. Fair complexion and thin body type. Pale tongue, Thin tongue coating, Soft and short pulse.

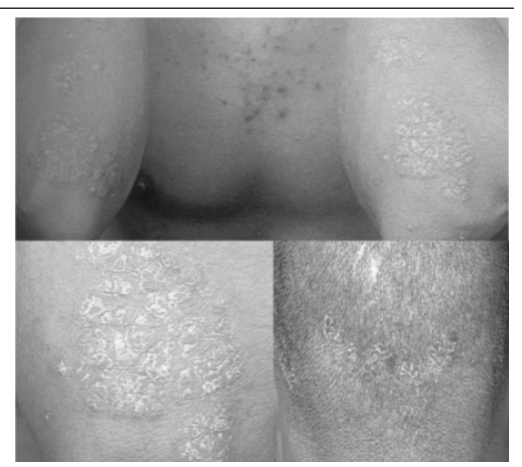

Case 6. Acne (Heat stagnation in the Spleen an Stomach Type)

\section{$\mathrm{M} / 17,173 \mathrm{~cm} / 75 \mathrm{Kg}$}

Symptoms that present small and raised bumps on the skin of chin and chest which secrete sebum when being popped have occurred since high-school. Pus is formed on several lesions. When they become worse, they turned red and were hardened. I feel achy when they were pressed and get a scar on some lesions. Whenever conditions got worse, a dermatologist drains pus and gives a steroid injection. Red face, Tend to overeat, Constipation, Yellow and greasy tongue coating, Slippery and rapid pulse.

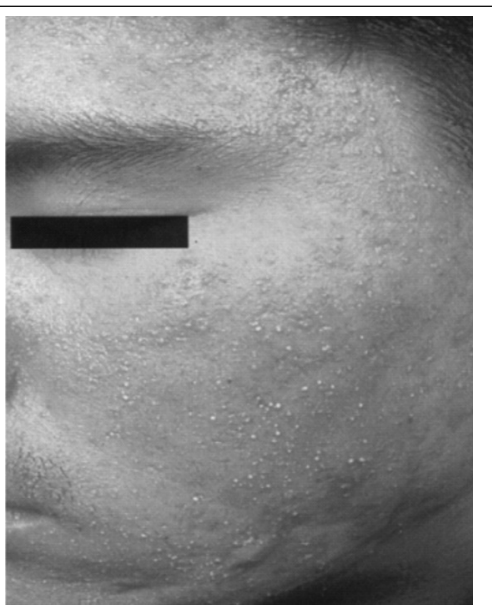

Table 2. Evaluation Form

\begin{tabular}{|c|c|}
\hline Characteristics & Evaluation \\
\hline \multirow{10}{*}{ Interviewing } & E1. Did the doctor identify a patient? \\
\hline & E2. Did the doctor create a good interview atmosphere (greetings, introduction, etc.)? \\
\hline & E3. Did the doctor use understandable terms? \\
\hline & E4. Did the doctor properly utilize non-verbal and verbal communication? \\
\hline & E5. Did the doctor give the patient enough opportunity to tell about his/her condition? \\
\hline & E6. Did the doctor structure and summarize information at the appropriate time? \\
\hline & E7. Did the doctor consider the patient's conditions from various angles? \\
\hline & E8. Did the doctor ask about major symptoms of skin disease? \\
\hline & E9. Did the doctor ask about referential symptoms (ROS, past history, family history, etc.)? \\
\hline & E10. Did the doctor give a sufficient explanation about symptoms and proper instruction about daily life habits? \\
\hline \multirow{5}{*}{ Skill } & E11. Did the doctor closely observe skin conditions (rubefaction, papule, scale, etc.)? \\
\hline & E12. Was writing of medical records in accordance with S-O-A-P? \\
\hline & E13. Did the doctor carry out proper diagnosis and herbal medicine treatment? \\
\hline & E14. Did the doctor appropriately conduct acupuncture? \\
\hline & E15. Did the doctor appropriately carry out external medical treatment? \\
\hline
\end{tabular}


Table 3. Questionnaire

\begin{tabular}{|c|c|}
\hline Characteristics & Questionnaire \\
\hline \multirow{3}{*}{ Interest } & Q1. The role-play class was exciting. \\
\hline & Q2. I actively participated in the role-play class. \\
\hline & Q3. I became more interested in the Korean Dermatology class after the role-play. \\
\hline \multirow{4}{*}{ Appropriateness } & Q4. The role-play was appropriate as a clinical clerkship program. \\
\hline & Q5. The role-play was appropriate as an evaluation tool of the clerkship program. \\
\hline & Q6. I would like to recommend the role-play to other departments. \\
\hline & Q7. I would like to recommend the role-play to junior's clerkship. \\
\hline \multirow{3}{*}{ Knowledge } & Q8. The role-play was useful in getting clinical knowledge. \\
\hline & Q9. The role-play was helpful in improving my diagnostic skill. \\
\hline & Q10. The role-play was helpful to improve my capability of observing skin lesions. \\
\hline \multirow{5}{*}{ Skill } & Q11. The role-play was useful to be aware of my current state of clinical skill. \\
\hline & Q12. The role-play was useful to improve my skill at diagnosis of cases and decision-making ability with herbal medicine. \\
\hline & Q13. The role-play was useful to upgrade my skill at acupuncture. \\
\hline & Q14. The role-play was useful to upgrade my skill at external medical treatment. \\
\hline & Q15. The role-play was useful to upgrade my skill at organizing and summarizing information, and writing medical records. \\
\hline \multirow{2}{*}{ Attitude } & $\begin{array}{l}\text { Q16. The role-play was useful to improve my patient consultation skills regarding the procedures of disease and } \\
\text { treatment, and related life habit factor. }\end{array}$ \\
\hline & $\begin{array}{l}\text { Q17. The role-play was useful to improve my patient consultation skills (interviewing atmosphere, appropriate } \\
\text { languages, etc.). }\end{array}$ \\
\hline \multirow{3}{*}{ General ability } & Q18. I gained confidence in applying clinical skill to patients through the role-play class. \\
\hline & Q19. The role-play class would be helpful to increase my ability to manage real life situations. \\
\hline & Q20. The role-play will become useful when I treat patients as a Korean medical doctor in the future. \\
\hline
\end{tabular}

value of Cronbach's $\alpha$, and in order to figure out the general features of the research target, frequency and percentage were estimated. Also, we assessed the mean, standard deviation, frequency of response and percentage from each questionnaire and evaluation form. To get the difference of evaluation scores according to the order of the role-play, we used t-test, setting up the significance level, $\mathrm{P}<0.05$.

\section{Result}

1. General features of research participants

At first, as a result of analyzing reliability of questionnaire and evaluation form, Cronbach's of the entire items were 0.878 and 0.901 . And among 79 students, 50 were male (63.3\%) and 29 were female (36.7\%). In addition, concerning age distribution, 21 25 years old were 48 students $(60.8 \%), 26 \sim 30$

Table 4. General Characteristics

\begin{tabular}{cccc}
\hline & \multicolumn{2}{l}{ Characteristics } & N $(\%)$ \\
\hline \multirow{2}{*}{ Gender } & Male & $50(63.3 \%)$ & $79(100 \%)$ \\
\cline { 2 - 3 } & Female & $29(36.7 \%)$ & $78(60.8 \%)$ \\
\cline { 2 - 3 } Age & $21 \sim 25$ years & $12(15.2 \%)$ & $79(100 \%)$ \\
\cline { 2 - 3 } & $26 \sim 30$ years & $19(24.0 \%)$ & \\
\hline
\end{tabular}


years old were 12 students (15.2\%), and over 31 years old were 19 students (24.0\%) (Table 4).

\section{Satisfaction with the role-play exercise}

A total of 20 questions were asked to students to assess their satisfaction level; the mean and standard deviation of each question are as follows (Table 5). Overall mean score of the total questions was 4.30. That of Q1 7 which are relevant to the satisfaction with the role-play as a clinical performance was 4.55 and of Q8 20 which correspond to effectiveness was 4.17 .

1) Method satisfaction aspect

Seven questions were about the interest and adequacy of the role-play as a clinical clerkship. The number of respondents and ratio of responses for each question are as follows (Table 6).

\section{2) Efficiency aspect}

Thirteen questions were about the efficiency of the role-play as an educational method. The number of respondents and ratio of responses for each question are as follows (Table 6).

\section{Score difference between the $1^{\text {st }}$ and $2^{\text {nd }}$ role-play}

We set up a t-test on 15 assessment questions to identify the score difference as the role-play proceeded. In 12 questions, except for E6 and E13, the $2^{\text {nd }}$ role-play had a higher mean score than the $1^{\text {st }}$ role-play. However, this difference was not statistically significant $(\mathrm{P}<0.05)$ (Table 7).

\section{1) Consultation ability}

Ten questions were assessed to figure out how much consultation ability was improved. The mean score of the $1^{\text {st }}$ doctor role group was 3.72 , while the

Table 5. Satisfaction Scores of the Role-play

\begin{tabular}{|c|c|c|c|c|c|}
\hline Characteristics & Q & & & & \\
\hline \multirow{3}{*}{ Interest } & Q1 & $4.69 \pm 0.49$ & \multirow{3}{*}{$4.58 \pm 0.48$} & \multirow{7}{*}{$4.55 \pm 0.44$} & \multirow{20}{*}{$4.30 \pm 0.44$} \\
\hline & Q2 & $4.56 \pm 0.59$ & & & \\
\hline & Q3 & $4.49 \pm 0.70$ & & & \\
\hline \multirow{4}{*}{ Appropriateness } & Q4 & $4.52 \pm 0.63$ & \multirow{4}{*}{$4.53 \pm 0.48$} & & \\
\hline & Q5 & $4.41 \pm 0.61$ & & & \\
\hline & Q6 & $4.38 \pm 0.72$ & & & \\
\hline & Q7 & $4.73 \pm 0.44$ & & & \\
\hline \multirow{3}{*}{ Knowledge } & Q8 & $4.50 \pm 0.70$ & \multirow{3}{*}{$4.33 \pm 0.63$} & \multirow{13}{*}{$4.17 \pm 0.49$} & \\
\hline & Q9 & $4.28 \pm 0.72$ & & & \\
\hline & Q10 & $4.21 \pm 0.78$ & & & \\
\hline \multirow{5}{*}{ Skill } & Q11 & $4.65 \pm 0.55$ & \multirow{5}{*}{$3.83 \pm 0.52$} & & \\
\hline & Q12 & $4.03 \pm 0.77$ & & & \\
\hline & Q13 & $2.74 \pm 0.96$ & & & \\
\hline & Q14 & $3.32 \pm 0.99$ & & & \\
\hline & Q15 & $4.44 \pm 0.69$ & & & \\
\hline \multirow{2}{*}{ Attitude } & Q16 & $4.44 \pm 0.70$ & \multirow{2}{*}{$4.42 \pm 0.65$} & & \\
\hline & Q17 & $4.34 \pm 0.65$ & & & \\
\hline \multirow{3}{*}{ General ability } & Q18 & $3.77 \pm 0.99$ & \multirow{3}{*}{$4.30+0.60$} & & \\
\hline & Q19 & $4.53 \pm 0.60$ & & & \\
\hline & Q20 & $4.61 \pm 0.59$ & & & \\
\hline
\end{tabular}


Table 6. Number and Percentage of Satisfaction Score

\begin{tabular}{|c|c|c|c|c|c|c|c|}
\hline & & $\begin{array}{l}\text { Strongly } \\
\text { disagree }\end{array}$ & Disagree & Moderate & Agree & Strongly agree & \\
\hline & & & & $N(\%)$ & & & \\
\hline \multirow{3}{*}{ Interest } & Q1 & & & $1(1.3)$ & $23(29.1)$ & $55(69.6)$ & $79(100)$ \\
\hline & Q2 & & & $4(5.1)$ & $26(32.9)$ & $49(62.0)$ & $79(100)$ \\
\hline & Q3 & & $1(1.3)$ & $6(7.6)$ & $24(30.4)$ & $48(60.8)$ & $79(100)$ \\
\hline \multirow{4}{*}{ Appropriateness } & Q4 & & & $5(6.3)$ & $31(39.2)$ & $43(54.4)$ & $79(100)$ \\
\hline & Q5 & & & $4(5.1)$ & $40(50.6)$ & $35(44.3)$ & $79(100)$ \\
\hline & Q6 & & $1(1.3)$ & $8(10.1)$ & $30(38.0)$ & $40(50.6)$ & $79(100)$ \\
\hline & Q7 & & & & $23(29.1)$ & $56(70.9)$ & $79(100)$ \\
\hline \multirow{3}{*}{ Knowledge } & Q8 & & $1(1.3)$ & $6(7.6)$ & 25 (31.6) & $47(59.5)$ & $79(100)$ \\
\hline & Q9 & & & $3(3.8)$ & $22(27.8)$ & $54(68.4)$ & $79(100)$ \\
\hline & Q10 & & $1(1.3)$ & $9(11.4)$ & $26(32.9)$ & $43(54.4)$ & $79(100)$ \\
\hline \multirow{5}{*}{ Skill } & Q11 & & $2(2.5)$ & $11(13.9)$ & $34(43.0)$ & $32(40.5)$ & $79(100)$ \\
\hline & Q12 & & $1(1.3)$ & $19(24.1)$ & $35(44.3)$ & $24(30.4)$ & $79(100)$ \\
\hline & Q13 & $5(6.3)$ & $28(35.4)$ & $30(38.0)$ & $11(13.9)$ & $5(6.3)$ & $79(100)$ \\
\hline & Q14 & $1(1.3)$ & $15(19.0)$ & $32(40.5)$ & $19(24.1)$ & $12(15.2)$ & $79(100)$ \\
\hline & Q15 & & & $9(11.4)$ & $27(34.2)$ & $43(54.4)$ & $79(100)$ \\
\hline \multirow{2}{*}{ Attitude } & Q16 & & $1(1.3)$ & $6(7.6)$ & $29(36.7)$ & $43(54.4)$ & $79(100)$ \\
\hline & Q17 & & & $8(10.1)$ & $32(40.5)$ & $39(49.4)$ & $79(100)$ \\
\hline \multirow{3}{*}{$\begin{array}{c}\text { General } \\
\text { ability }\end{array}$} & Q18 & $1(1.3)$ & $7(8.9)$ & $23(29.1)$ & $27(34.2)$ & $21(26.6)$ & $79(100)$ \\
\hline & Q19 & & & $4(5.1)$ & $29(36.7)$ & $46(58.2)$ & $79(100)$ \\
\hline & Q20 & & & $4(5.1)$ & $22(27.8)$ & $53(67.1)$ & $79(100)$ \\
\hline
\end{tabular}

Table 7. Statistical Analysis of the Scores of the 1st, and the 2nd Role-play, Using t-test

\begin{tabular}{|c|c|c|c|c|}
\hline & & $\begin{array}{c}\text { 1st Doctor Role } \\
\qquad \begin{array}{c}\mathrm{N}=41 \\
\mathrm{M} \pm \mathrm{SD}\end{array}\end{array}$ & $\begin{array}{c}\text { 2nd Doctor Role } \\
\mathrm{N}=38 \\
\mathrm{M} \pm \mathrm{SD}\end{array}$ & $\mathrm{p}$ \\
\hline \multirow{11}{*}{ Interviewing } & E1 & $4.00 \pm 0.77$ & $4.05 \pm 0.57$ & .102 \\
\hline & E2 & $3.83 \pm 0.89$ & $3.87 \pm 0.78$ & .329 \\
\hline & E3 & $3.98 \pm 0.65$ & $4.05 \pm 0.66$ & .850 \\
\hline & E4 & $3.83 \pm 0.83$ & $4.03 \pm 0.68$ & .071 \\
\hline & E5 & $3.93 \pm 0.52$ & $3.95 \pm 0.66$ & .415 \\
\hline & E6 & $3.68 \pm 0.61$ & $3.63 \pm 0.79$ & .093 \\
\hline & E7 & $3.49 \pm 0.81$ & $3.79 \pm 0.84$ & .536 \\
\hline & E8 & $3.17 \pm 0.74$ & $3.63 \pm 0.79$ & .408 \\
\hline & E10 & $3.59 \pm 0.77$ & $3.84 \pm 0.79$ & .336 \\
\hline & E11 & $3.73 \pm 0.87$ & $3.95 \pm 1.04$ & .454 \\
\hline & $\begin{array}{l}\mathrm{Sub} \\
\text { total }\end{array}$ & $3.72 \pm 0.47$ & $3.88 \pm 0.54$ & .814 \\
\hline \multirow{6}{*}{ Skill } & E9 & $3.22 \pm 0.99$ & $3.34 \pm 0.85$ & .151 \\
\hline & E12 & $3.63 \pm 0.80$ & $3.68 \pm 0.74$ & .403 \\
\hline & E13 & $3.63 \pm 0.73$ & $3.60 \pm 0.68$ & .773 \\
\hline & E14 & $3.56 \pm 0.95$ & $3.77 \pm 0.87$ & .623 \\
\hline & E15 & $3.54 \pm 0.81$ & $3.54 \pm 0.98$ & .134 \\
\hline & Sub total & $3.51 \pm 0.59$ & $3.60 \pm 0.63$ & .861 \\
\hline \multicolumn{2}{|c|}{ Total } & $3.65 \pm 0.43$ & $3.79 \pm 0.53$ & .235 \\
\hline
\end{tabular}


$2^{\text {nd }}$ doctor role group was 3.88. The $2^{\text {nd }}$ group had a higher score but there was no significant difference.

\section{2) Clinical skill}

Five questions were assessed to figure out how much clinical skill was enhanced. The mean score of the $1^{\text {st }}$ doctor role group was 3.51 , while the $2^{\text {nd }}$ doctor role group was 3.60 . The $2^{\text {nd }}$ group had a higher score but there was no significant difference.

\section{Discussion \& Conclusion}

The roles of primary physicians are to be equipped with basic clinical knowledge and to treat a patient based on discovered problems by comprehending various clinical situations. Since physicians conducting these roles need a balanced capacity in three parts, being knowledge, skills and attitude, medical colleges should provide students with opportunities to learn these three aspects equally. Given the reality that Korean medical students mostly engage in primary care after graduation, there are problems which do not satisfy the objective of clinical training because clinical training education based on passive-observation such as visiting outpatient clinics, lectures, ward rounds is not able to offer concrete experience required for understanding actual situations in clinic ${ }^{16)}$.

In order to make up for those problems in clinical training education, simulation training methods have been attracting attention and role-play is one type of simulation, along with standardized patients and mannequins. Learning methods using a patient simulator have advantages because they can reduce the gap between theory and practice by repetitively practicing patient cases under secure conditions where patients are not harmed and under conditions similar to actual situations. In addition, students can effectively apply their knowledge, and they can get a grip on correct and insufficient parts of their decision-making process through feedback ${ }^{17)}$. There are several studies showing that role-play is suitable for students to enhance satisfaction about clinical practice training, confidence, and learning motivation, and to improve critical thinking and decision making ability in clinic ${ }^{18-20)}$.

Although the importance of effective clinical practice training has been emphasized for real clinical practice, in Korean medical colleges, only one college has instituted OSCE and CPX, and related research is also deficient. Therefore, our department estimated the efficacy of role-play in clinical practice training by attempting role-play similar to actual tasks and did a survey on student satisfaction and evaluated the improvement of students' skill and interview ability.

Two students were randomly selected out of 79 seniors during dermatology clinical practice. First, one student took the doctor's role and the other played the patient's role while a medical resident observed the role-play. After finishing the first role-play, they swapped roles and carried out the second role-play using another clinical case. When the two role-plays had been completed, the medical resident gave a brief account of the cases and took some time for discussion about what went well and what needs to be improved in role-play with the students. Then, the students filled in a questionnaire about their satisfaction level with clinical practice training, while the medical resident evaluated the ability of the students who played the doctor role in terms of interviewing skills and compared the score acquired in the $1^{\text {st }}$ role-play and that of the $2^{\text {nd }}$ role-play.

For the total 20 survey questions and 15 assessment questions, each reliability coefficient was 0.901 and 0.878 respectively, showing internal coherency as a research tool. Among 79 seniors who participated in the clinical clerkship of dermatology department, 50 students were male $(63.3 \%)$ and 29 students were female $(36.7 \%)$. In terms of age distribution, 48 students were 21 25 years old 
(60.8\%), 12 students were $26 \sim 30$ years old (15.2\%), and 19 students were over 31 years old $(24.0 \%)$. Out of two role-plays, in the $1^{\text {st }}$ role-play, 41 students took doctor's role and in the $2^{\text {nd }}$ role-play, 38 students took a doctor's role.

According to survey results, considering that the total average score of all questions was 4.30 it seems like the satisfaction of role-play as a clinical practice method is quite high. As a result of questionnaire analysis, in terms of method satisfaction (Q1-7) about interest and appropriacy as educational methods, the total average score was 4.55. Among questions, 'Q7. I would like to recommend role-play to junior's clerkship.' accounts for the highest score of 4.73 and 'Q1. The role-play class was exciting.' took the second highest score of 4.69. Even though 'Q6. I would like to recommend role-play to other departments.' gained the lowest score of 4.38, we can notice that students consider role-play as a satisfactory and interesting clinical training method in view of the fact that the score results showed a high proportion of 3 to 5 points on the whole

Where it covers availability (Q8-20) composed of knowledge, skill, attitude, and general ability, the total average score was 4.17 points which is lower than the total average score of method satisfaction. 'Q11. The role-play was useful to be aware the current state of my clinical skill.' received the highest score of 4.65, and this result indicates that by contrast to conventional knowledge acquisitionoriented education, students were able to recognize their own conditions by actively participating in role-play similar to the actual environment. This is similar to the results, telling that most students are aware of the necessity for knowledge acquisition and in which part they needed supplementary study after simulation training ${ }^{17)}$ and therefore it seems that role-play contributes to arousing motivation for studying. On the other hand, 'Q13. The role-play was useful to upgrade my skill of acupuncture.' and 'Q14. The role-play was useful to upgrade my skill of external medical treatment.' got relatively low scores of 2.74 and 3.32 respectively. This reflects the idea that it is difficult to improve the skill of acupuncture and external medical treatment through just a one-time experience.

We collected descriptive comments from students about pros and cons and any improvement for the role-play. There were many opinions like 'I could gain confidence by facing a real environment, giving medical treatment and realized which part I had to study harder because I found out where I was insufficient.', 'I got to know my skills and interviewing ability objectively.', 'I was interested in the role-play and it brought on the promotion of grasp about diseases.' and 'I liked getting feedback.' As for the disadvantages, there are opinions such as 'If I lack knowledge about disease, it would not be so helpful.', and 'The role-play ran short of reality due to a mismatch between a real patient and the student who pretended to be a patient, I wanted to treat a real patient with consent.' Also, there were comments like 'I would like to perform a role-play with various diseases' 'It should be carried out regularly rather than just one time.'

To determine whether students' skill and interview ability improve according to the progress of the role-play, we compared the $1^{\text {st }}$ scores with the $2^{\text {nd }}$ scores of the role-play. The total 15 evaluation items are comprised of one assessment part for interview ability such as making a good interview atmosphere, using easy and understandable terms, making use of non-verbal communication, asking questions from various angles and listening to patients' words attentively and the other assessment part for skills such as observing skin conditions, making a proper diagnosis and choosing right treatment methods. For 12 out of 15 items, the scores of the $2^{\text {nd }}$ role-play were higher than those of the $1^{\text {st }}$ role-play, but these were not statistically significant $(\mathrm{P}<0.05)$. As shown in the result that 'E6. Does a doctor structure and summarize information at the appropriate time?' 
takes the score of 3.68 in the $1^{\text {st }}$ role-play and 3.63 in the $2^{\text {nd }}$ role-play, the question got a lower grade as the role-play proceeded. This seems to be because it is hard to improve capacity of organizing and summarizing information in one or two role-play exercises and it seems that it is necessary to practice several times. 'E13. Does a doctor carry out proper diagnosis and herbal medicine treatment?' also occupies a lower grade in the $2^{\text {nd }}$ role-play (3.6 points) than in the $1^{\text {st }}$ role-play (3.63 points); the cause of this result is likely that making a proper diagnosis and treatment depends on differences in students' usual knowledge.

We got descriptive comments from the students who acted as the doctor in the $2^{\text {nd }}$ role-play about differences when they performed the role-play after observing the student who acted as the doctor in the $1^{\text {st }}$ role-play. Considering that there were many opinions like 'I was not able to omit the parts overlooked in the $1^{\text {st }}$ role-play.', 'I could make up for the faults found in the $1^{\text {st }}$ role-play.', 'I could take account of something to be desired from taking the patient's role in the $1^{\text {st }}$ role-play.', we knew that recursive role-play was effective in learning. In fact, there was a result that interview technique was advanced in real patient consult after carrying out role-play ${ }^{21)}$.

This study was insufficient to draw out a conclusion about what effects the role-play has on clinical training in that the number of students was too small as only 79 seniors from one Korean medical school participated, the training period was so limited that role-play was not able to be conducted repeatedly, and cases were assigned to students regardless of their academic levels. Like students' opinions such as 'I wish that role-play could be adopted to clinical training of other classes.', 'I would like to role-play again after acquiring enough knowledge.', if diverse cases with various diseases and a number of different levels of cases are developed besides dermatological disease, role-play class would motivate students to study and help them to learn about the knowledge, skill and attitude of the related disease. Also, while this research has conducted the role-play after a brief explanation about three dermatological diseases was given to students for three hours, to be more effective, more organized and sufficient preparation is required such as assigning discussion time about the case after watching one explanatory role-play, and giving a lecture to improve the consultation skill.

Research on the role-play and its effectiveness in clinical performance in the Korean medical school is rarely found. Therefore, even though this research needs to be improved as stated earlier, it is meaningful as a fundamental study for the improvement of the quality of clinical performance education in Korean medical school henceforward. If current clinical clerkship is developed through continuous research and development, it would be able to provide better clinical clerkship education that enhances skill and consultation ability as well as knowledge.

\section{References}

1. Park JH. Medical Students' Attitudes Toward the Patient-Doctor Relationship. Korean Journal of Medical Education. 2007;19(3):215-23.

2. McManus IC, Richards P, Winder BC. Clinical experience of UK medical students. The Lancet. 1998;351:802-3.

3. Cartwright MS, Reynolds PS, Rodriguez ZM, Breyer WA, Cruz JM. Lumbar puncture experience among medical school graduates: the need for formal procedural skills training. Medical education. 2005;39:437.

4. Ringsted C, Schroeder TV, Henriksen J, Ramsing B, Lyngdorf P, Jnsson V, et al. Medical students' experience in practical skills is far from 
stakeholders' expectations. Medical Teacher. 2001;23:412-6.

5. Weinberger M, Greene JY, Mamlin JJ. The impact of clinical encounter events on patient and physician satisfaction. Soc Sci Med E. 1981;15:239-44.

6. Korsch BM, Gozzi E K, Francis V. Gaps in doctor-patient communication. I . Doctor-patient interaction and patient satisfaction. Pediatrics 1968;42:855.

7. Lehmann F, Fontaine D, Bourque A, Cote L. Measurement of patient satisfaction: The Smith-Falvo patient-doctor interaction scale. Can Fam-Physician. 1988;34:2641-5.

8. Hiltin TF, Butler MC, Nice DS. Patient and provider satisfaction in Navy family practice and non-family practice clinics. J Fam Prac. 1984; 18(4);569-73.

9. Makoul G. Communication skills education in medical school and beyond. JAMA. 2003;289-93.

10. Janicik RW, Kalet A, Schwartz M, Lipkin, M, Zabar S. Using bedside rounds compared with other methods to teach communication skills in clinical clerkships. JGIM. 2002;17:228-32.

11. Bradley P. The history of simulation in medical education and possible future directions. Medical education. 2006;40:254-62.

12. Barzansky B, Etzel SI. Educational programs in US medical schools, 2004-2005. JAMA. 2005;294:1068-74.

13. Kim KS, Kim KH, Choi CH, Lee SJ, Kim BS. Study on Pulse Simulator of Korean Medicine for Objective Structured Clinical Examination (OSCE). J Korean Korean Med. 2011; 32(1):1-11.

14. Lee HW, Hong SW. Study of Standardized Patient Program Using Case Report of Atopic Dermatitis. J Korean Korean Med. 2011; 32(5): 78-89.

15. Song MK, Hong SW. A Survey of Students' Satisfaction on Participation Learning Using Role-play in Clerkship. The Journal of Korean Korean Medical Ophthalmology \& Otolaryngology \& Dermatology. 2012;25(3):65-77.

16. Beeson SA, Kring DL. The effects of two teaching methods on nursing students' factual knowledge and performance of psychomotor skills. J Nurs Educ. 1999;38(8):357-9.

17. You EY. Medical Simulation. J Korean Med Assoc. 2005;48(3):267-76.

18. Gomez GE, Gomez EA. Learning of psychomotor skills: Laboratory versus patient care setting. J Nurs Educ. 1987;26:20-24.

19. Jarzemsky PA, McGrath J. Look Before You Leap: Lessons Learned When Introducing Clinical Simulation. Nurse Educator. 2008;33(2): 90-95.

20. Lasater K. High-Fidelity Simulation and the Development of Clinical Judgment: Students' Experiences. J Nurs Educ. 2007;46(6):269-276.

21. Lee JH, Sgin JS, Suh DH, Eun HC. Evaluation of the Outcome of Communication Skill Training Using a Role Play Model in the Dermatological Clerkship. Korean J Dermatology. 2004;42(11): 1440-48. 